\title{
Low-Cost GPS Receivers for the Monitoring of Sunflower Cover Dynamics
}

\author{
Mehrez Zribi, ${ }^{1}$ Erwan Motte, ${ }^{1}$ Pascal Fanise, ${ }^{1}$ and Walid Zouaoui ${ }^{2}$ \\ ${ }^{1}$ CESBIO (CNRS/IRD/CNES/UPS), 18 avenue Edouard Belin, 31401 Toulouse Cedex 9, France \\ ${ }^{2}$ ENET'COM, Université de Sfax, route Soukra Km 3.5, Sfax, Tunisia
}

Correspondence should be addressed to Mehrez Zribi; mehrez.zribi@ird.fr

Received 12 June 2017; Revised 20 September 2017; Accepted 28 September 2017; Published 25 October 2017

Academic Editor: Francesco Dell'Olio

Copyright (c) 2017 Mehrez Zribi et al. This is an open access article distributed under the Creative Commons Attribution License, which permits unrestricted use, distribution, and reproduction in any medium, provided the original work is properly cited.

\begin{abstract}
The aim of this research is to analyze the potential use of Global Navigation Satellite System (GNSS) signals for the monitoring of in situ vegetation characteristics. An instrument, based on the use of a pair of low-cost receivers and antennas, providing continuous measurements of all the available Global Positioning System (GPS) satellite signals is proposed for the determination of signal attenuation caused by a sunflower cover. Experimental campaigns with this instrument, combined with ground truth measurements of the vegetation, were performed over a nonirrigated sunflower test field for a period of more than two months, corresponding to a significant portion of the vegetation cycle. A method is proposed for the analysis of the signal attenuation data as a function of elevation and azimuth angles. A high correlation is observed between the vegetation's water content and the GPS signals attenuation, and an empirical modeling is tested for the retrieval of signal behavior as a function of vegetation water content (VWC). The VWC was estimated from GNSS signals on a daily basis, over the full length of the study period.
\end{abstract}

\section{Introduction}

As the vegetation cover affects various physical exchange processes, in particular the water cycle, absorption and reemission of solar radiation, carbon cycling, and latent and sensible heat fluxes, it plays a key role in land surface processes $[1,2]$. Any change in vegetation cover can thus have a strong influence on the environment, at local, regional, and even global scales. Over the last three decades, optical and microwave remote sensing techniques have been used to retrieve global vegetation characteristics [3-5]. Optical observations have made a considerable contribution to the estimation of biophysical vegetation parameters, such as the Leaf Area Index (LAI) and vegetation water content. In this context, it has been proposed to use various indices, such as the Normalized Difference Vegetation Index (NDVI), to analyze the distribution and potential photosynthetic activity of vegetation [4]. Furthermore, several studies have also assessed the sensitivity of Synthetic Aperture Radar (SAR) signals to vegetation conditions, at several different radar wavelengths (mainly the L, C, and X bands) $[4,6]$. It is known that the behavior of backscattered radar signals is directly related to the dielectric constant and geometric structure of the vegetation cover.

The availability of navigation signals transmitted by Global Navigation Satellite System (GNSS) constellations such as the Global Positioning System (GPS) has created a whole new branch of remote sensing based on the study of their interactions with the earth surface. One of the most outstanding examples is the GNSS reflectometry (GNSS-R), where the navigation signals are used in a bistatic radar configuration [7] to sense oceans, soil moisture, snow and ice, vegetation, and forest characteristics $[8,9]$. In the specific case of vegetation measurements, several GNSS-R techniques have demonstrated their potential: a single antenna approach with dedicated linearly polarized receivers [10] or commercial geodetic receivers [11]. A dual antenna approach can also be used $[12,13]$.

More recently, a small number of studies have also interpreted the attenuation of direct GNSS signals, in an attempt to make local estimations of various land surface parameters. The first of these demonstrated the strong potential of GNSS 
signal interpretation for the estimation of local snow coverage or ground moisture content $[14,15]$, as well as the estimation of the vegetation water content in forest fields [16, 17]. Reference [14] analyzes the attenuation of signals emitted by GPS systems, using continuous low-cost GPS measurements during the snow melt period. They illustrate the potential of this approach for the continuous determination of snow liquid water content. The same technique has been applied by [15] for the retrieval of soil moisture, by considering variations in the L1-band GPS signal strength to be caused by changes in soil permittivity. The vegetation water content in a forest of deciduous trees was estimated by [17], by analyzing measurements of GPS signals in the open sky and under the vegetation layer. A high potential of this technique was demonstrated for estimation of vegetation water content of tree leaves.

In the case of in situ measurements, vegetation water content is generally estimated through the use of an approach, based on cutting vegetation samples, and comparing their original and dried weights. This methodology is destructive, time consuming, and laborious. In the present study, our aim is to analyze the attenuation of GNSS signals received beneath a sunflower cover, in order to estimate the water content of local vegetation. We adapt the approach proposed for forest by [17] for an annual agriculture cover. This approach is based on the analysis of GNSS signals, using an instrument comprising two commercial, low-cost GPS receivers, with their respective antennas positioned above and below the vegetation cover of interest. In the second section we provide a detailed description of this instrument. Section 3 describes the experimental campaigns, which were carried out in a sunflower test field. The results produced by analyzing the data are discussed in Section 4. Our conclusions are presented in Section 5.

\section{Proposed Methodology}

2.1. GPS Receiver Description. The proposed instrument (Figure 1) comprises two antennas: one attached to a mast and located above the maximum estimated height of the vegetation (i.e., $\sim 2 \mathrm{~m}$ ), used as the reference antenna $(R)$, and the other installed at ground level $(G)$. Each antenna is attached to a low-cost, commercial GPS receiver able to simultaneously record the carrier-to-noise power density ratio $(\mathrm{C} / \mathrm{N} 0)$ of up to 15 GNSS satellites, with a resolution of $0.1 \mathrm{~dB}-\mathrm{Hz}$, and a temporal resolution of $1 \mathrm{~s}$. The measured value of $\mathrm{C} / \mathrm{N} 0$ quantifies the quality of the transmission channel and can be directly related to the attenuation. The GPS carrier signals are centered at $1575.42 \mathrm{MHz}$ (L1 carrier).

The main components of the instrument are listed as follows:

(i) Two low-cost Maestro A2200 GPS receivers based on the SirFstarIV chip, using the One Socket Protocol [18]. This chip has sufficient sensitivity to determine the values of $\mathrm{C} / \mathrm{N} 0$ for each satellite, with a resolution of $0.1 \mathrm{~dB}-\mathrm{Hz}$, once per second.

(ii) Two similar, low-cost, waterproof, active magnetmount omnidirectional antennas.

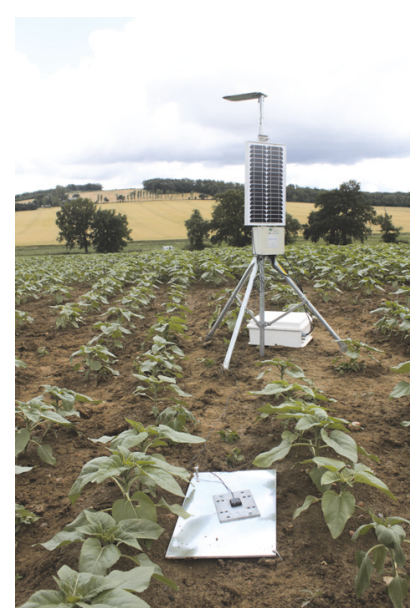

FIGURE 1: Photograph of the GNSS receiver-based instrument, showing the solar panel, receiver, and two antennas $((G)$ on the ground and $(R)$ above the foliage).

(iii) One low-cost, single-board, low-power microcontroller (Arduino MEGA2560) with storage (SD card).

(iv) One power supply (battery with solar panels).

(v) A 2-3-meter high mast or support for the reference antenna

The total cost of this setup is estimated to be approximately 500 USD but could be further reduced by integrating the GPS chips and the microcontroller onto a customized board.

2.2. Theoretical Discussion. The reference signal could be provided by the antenna on the mast, above the vegetation $(R)$, whereas the signals attenuated by the vegetation were recorded directly at ground level $(G)$.

In [17], the power received by the instrument antennas was used to compute the attenuation due to the vegetation, as follows:

$$
\frac{P_{G}}{P_{R}}=\frac{\left|L \cdot E_{G}\right|^{2}}{\left|E_{R}\right|^{2}}=|L|^{2} \frac{\left|E_{0 i} \cdot e^{j \phi_{G}}\right|^{2}}{\left|E_{0 i} \cdot e^{j \phi_{R}}\right|^{2}}=|L|^{2},
$$

where $P_{G}$ and $P_{R}$ are the power levels received by the antennas $G$ and $R$, respectively, $L$ is the attenuation due to the vegetation, $E_{0 i}$ is the amplitude of the incident electric field, and $\phi_{R}$ and $\phi_{G}$ are the phases of the incident electric field for each instrument.

However, in the case of the present study the instrumental configuration is slightly different to that of [17]: as the radiation diagrams of the two low-cost antennas are slightly different, the attenuation cannot be analyzed using the signals recorded by the mast antenna. The latter is used only to identify the influence of strong atmospheric perturbations, which can affect the strength of the incident GPS signals. In the case of the present study, the reference power without attenuation $\left(P_{R}\right)$ was taken to be the power measured by the ground level-antenna measurements on the first day of the 
campaign, thus corresponding to the surface signal obtained under conditions of a highly dispersed vegetation cover.

It is thus straightforward to compute the signal attenuation as [17]

$$
L=\sqrt{\frac{P_{G}}{P_{R}}} .
$$

This approximation does not take into account the effects of refraction and reflection inside the vegetation itself.

This attenuation is directly related to the optical thickness of the vegetation, $\tau[17,19]$, measuring the degree of transparency of vegetation and then the fraction of electromagnetic radiation scattered or absorbed by the vegetation layer, using

$$
L=\exp \left[\frac{\tau}{\cos \left(\theta_{i}\right)}\right],
$$

where $\theta_{i}$ is the incidence angle of GNSS signals.

$\tau$ can be expressed as a function of the Vegetation Water Content (VWC) [19, 20]:

$$
\tau=b \cdot \mathrm{VWC},
$$

where $b$ is a factor depending on the type of vegetation.

\section{Campaigns and Databases}

3.1. Studied Test Field. An experimental campaign was held during the summer of 2016, to study and compare the attenuation of GPS signals on a sunflower field (Figure 1); at the same time, approximately biweekly in situ measurements were carried out, in order to obtain direct measurements of the sunflowers water content.

The test field is located southwest of Toulouse (France), in the municipality of Auradé, at the geographic coordinates $43^{\circ} 32^{\prime} 50^{\prime \prime} \mathrm{N}, 1^{\circ} 06^{\prime} 21^{\prime \prime} \mathrm{E}$. For a period of more than two months, between June 16th and August 22, 2016, the GNSS instrument was installed in a sunflower test field, as shown in Figure 1. As the sunflowers were sown at the end of May, at the beginning of the experimental campaign the vegetation cover was still very short (approximately $20 \mathrm{~cm}$ in height), with a relatively low density. The sunflower rows had a spacing of approximately $60 \mathrm{~cm}$, and the field was not irrigated.

3.2. Ground Truth Measurements. During the GNSS signal acquisitions, two types of vegetation measurement were performed: VWC and crop height. Seven sets of in situ measurements of these two parameters were recorded, on different dates, during the GNSS campaign. For the VWC measurements at ground level, on each of these dates we cut $2 \mathrm{~m}^{2}$ of vegetation cover samples and then computed the difference in the samples' weight, between its initial value and that obtained following $48 \mathrm{~h}$ of drying in an oven. The temporal dynamics of the VWC are presented in Table 1, showing that this parameter increased continuously over a period of 1.5 months, ending in early August, following which the plants began to dry, as shown by the measured
TABLE 1: Temporal dynamics of the sunflowers' VWC and height.

\begin{tabular}{lcc}
\hline Date & VWC $(\mathrm{kg} / \mathrm{m} 2)$ & Height $(\mathrm{cm})$ \\
\hline $16 / 06 / 2016$ & 0.193 & 25 \\
$23 / 06 / 2016$ & 0.768 & 38 \\
$30 / 06 / 2016$ & 2.072 & 63 \\
$08 / 07 / 2016$ & 2.751 & 104 \\
$21 / 07 / 2016$ & 2.985 & 120 \\
$03 / 08 / 2016$ & 6.256 & 140 \\
$22 / 08 / 2016$ & 2.657 & 140 \\
\hline
\end{tabular}

decrease in water content. Concerning the height of the vegetation, a mean height of 10 plants is considered for each date. This reached a maximum of approximately $140 \mathrm{~cm}$ at the end of July. Figure 2 includes six consecutive views of the studied field, illustrating the temporal dynamics of the vegetation throughout the campaign. Continuous growth of the vegetation was observed until the end of July, followed by a relatively dry period during the last three weeks, with no further growth.

3.3. GNSS Data Availability. Figure 3 is a $2 \mathrm{D}$ polar histogram, showing the average weekly number of 1-second GPS signal observations per $10 \times 10$-degree elevation-azimuth bin. As expected from the location of the instrument and the GPS constellation configuration, no satellites signal originates from the northern sector. The elevation coverage is good (except at elevations greater than 80 degrees). The greatest number of satellite observations were recorded at azimuths of approximately $+/-60^{\circ}$, as could also be expected from the orbital geometry of the GPS constellation and the receiver's location. Overall, it can be seen that these distributions are rather nonuniform as a function of their spherical coordinates in the sky but that a sufficient volume of reliable data was retrieved for the purposes of the study with more than 10,000 individual 1 -second measurements per week, per $10 \times$ 10-elevation-azimuth bin. In addition, it should be noted that throughout the entire campaign, the $\mathrm{C} / \mathrm{N} 0$ of the reference signal for a given elevation angle bin was approximately constant.

\section{Analysis of the Experimental Data}

4.1. Azimuthal Behavior of the GNSS Signals Attenuation. In the following sections, we consider the vegetation-induced attenuation as defined in (1) (in $\mathrm{dB}$ ) for data analysis.

Figure 4 plots the weekly averaged ground signal attenuation, for the nine studied weeks, as a function of satellite elevation and azimuth $\left(10^{\circ} \times 10^{\circ}\right.$ bins $)$. Firstly, the nine diagrams in this figure illustrate the significant dynamics of the GNSS signal attenuation as a function of time. This attenuation is found to increase until the end of July and then to progressively decrease during the last three weeks of the campaign. This behavior is illustrated in the mean values of the signals of the different weekly diagrams (Figure 4). The weekly standard deviation values of the same signals do not 


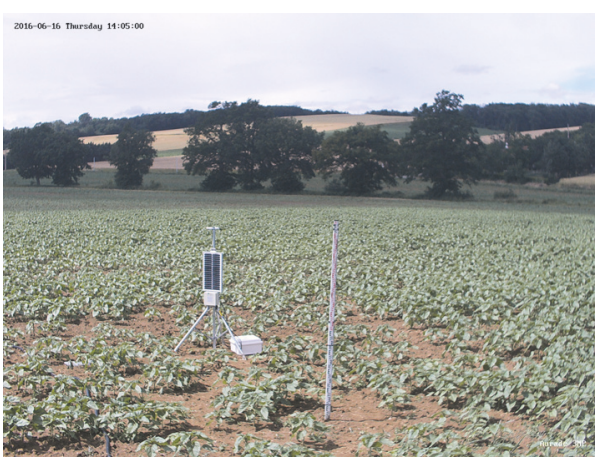

(a)

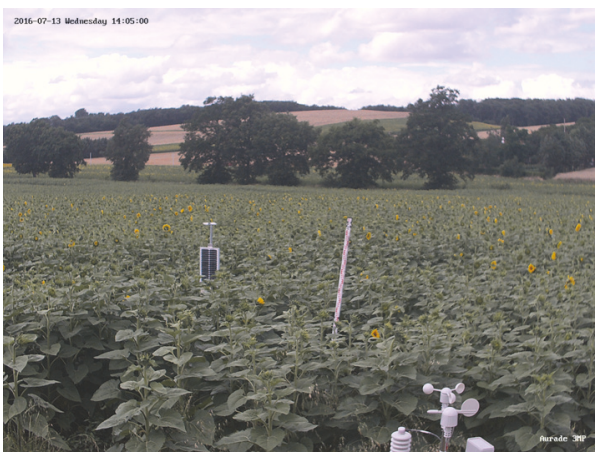

(c)

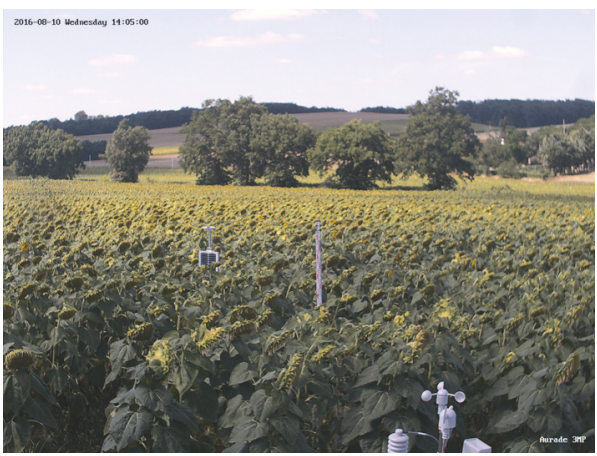

(e)

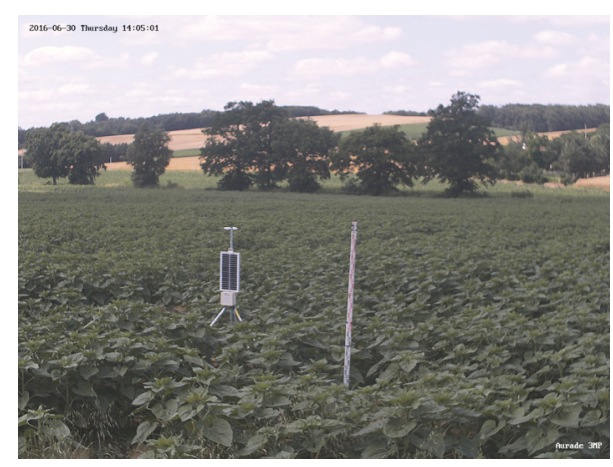

(b)

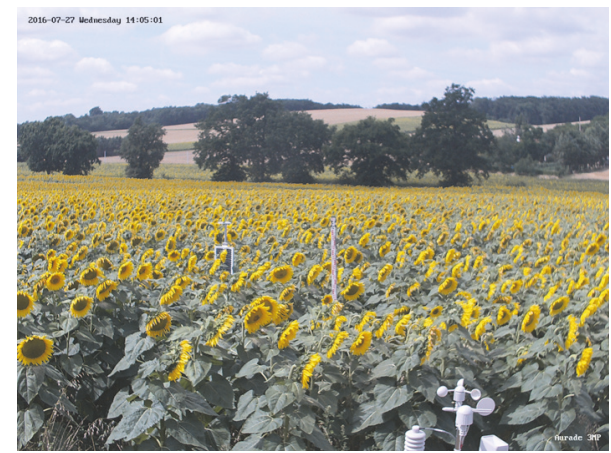

(d)

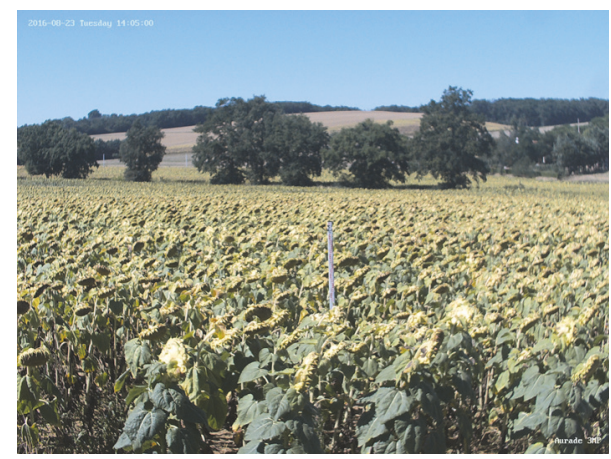

(f)

Figure 2: Photographs of the test field on six consecutive dates: (a) 16/06/2016, (b) 30/06/2016, (c) 13/07/2016, (d) 27/07/2016, (e) 10/08/2016, and (f) $23 / 08 / 2016$.

show a temporal tendency; retrieved values are approximately stable with the exception of the first week corresponding to highly dispersed vegetation cover.

Furthermore, an azimuthal dependence can be observed in this figure: starting in July, weaker attenuation (a stronger ground signal) can be observed for azimuths close to $200^{\circ}$, corresponding to the alignment of the rows of sunflowers. The reduced presence of vegetation cover in this direction leads to a reduction in signal attenuation. This azimuthal dependence is weakened when the vegetation cover flourishes during the last weeks of the campaign. With respect to these conditions, the azimuths orthogonal to the row alignment reveal an increased level of attenuation, at $\left(110-120^{\circ}\right)$ and at $\left(290-300^{\circ}\right)$. Other flux measurement instruments were located in the vicinity of our setup, at an azimuth of approximately $90^{\circ}$. In order to ensure that these features could not affect the analysis, signals originating from azimuths of $90^{\circ}+/-20^{\circ}$ were not considered. This is presented in the following section, which discusses the dynamic behavior of the GNSS signals as a function of elevation.

4.2. GNSS Signal Dynamics as a Function of Time and Elevation Angle. Figure 5 plots the daily mean value of GNSS signal attenuation as a function of time, for three elevation angle intervals $\left(25-45^{\circ}, 45-65^{\circ}, 65-85^{\circ}\right)$ and all azimuths except $90^{\circ}+/-20^{\circ}$. As shown in Figure 3, very little data was recorded at elevations greater than $85^{\circ}$. In addition, data recorded at elevations below $25^{\circ}$ was not used, to avoid 


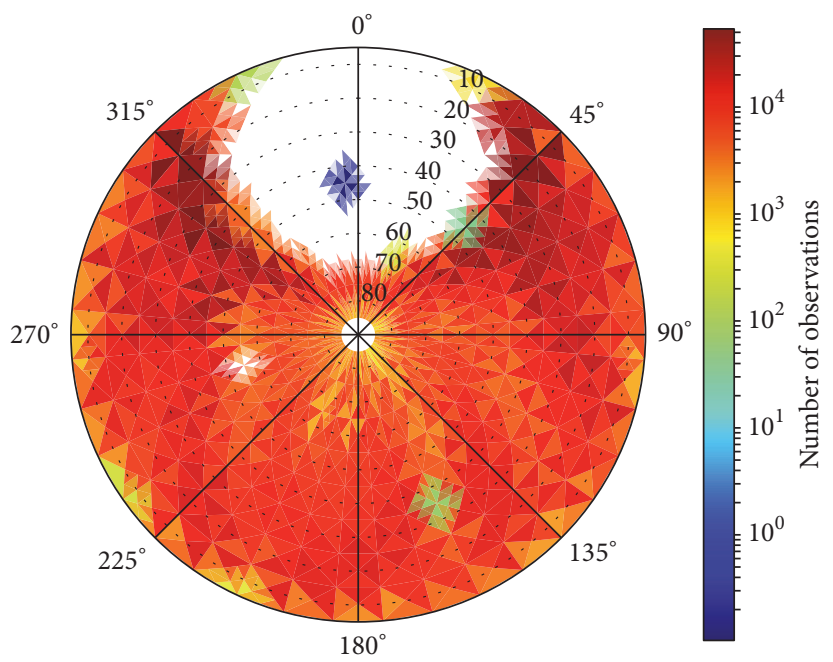

FIGURE 3: Distribution of GNSS reference signals (average number of 1-second observations) as a function of elevation and azimuth angles $(10 \times 10$-degree bins) for 1 week.

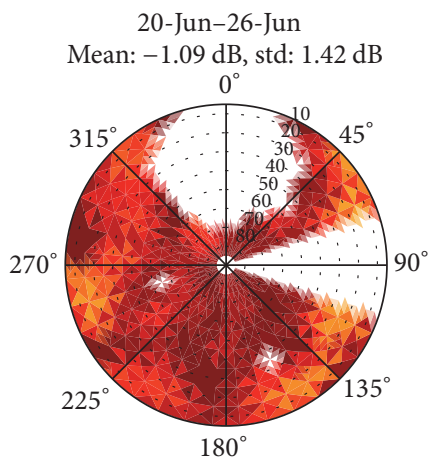

11-Jul-17-Jul

Mean: $-4.86 \mathrm{~dB}$, std: $2.72 \mathrm{~dB}$

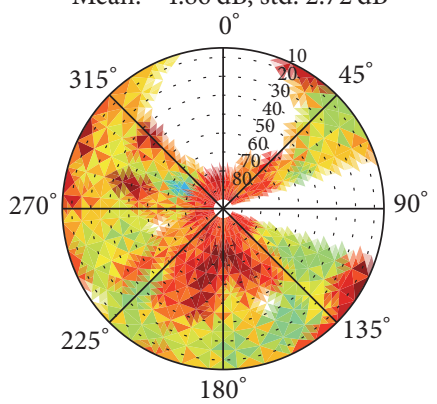

01-Aug-07-Aug

Mean: $-5.60 \mathrm{~dB}$, std: $2.87 \mathrm{~dB}$

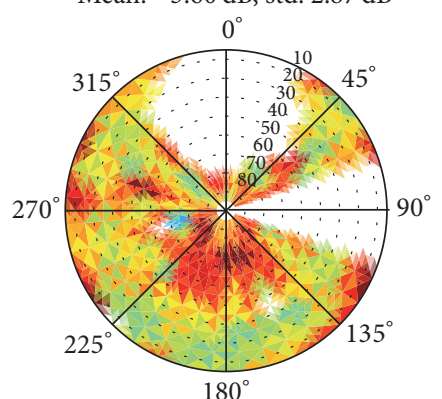

27-Jun-03-Jul

Mean: $-2.46 \mathrm{~dB}$, std: $2.14 \mathrm{~dB}$

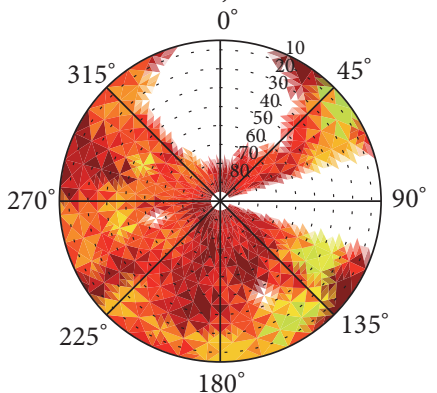

18-Jul-24-Jul

Mean: $-5.36 \mathrm{~dB}$, std: $2.74 \mathrm{~dB}$

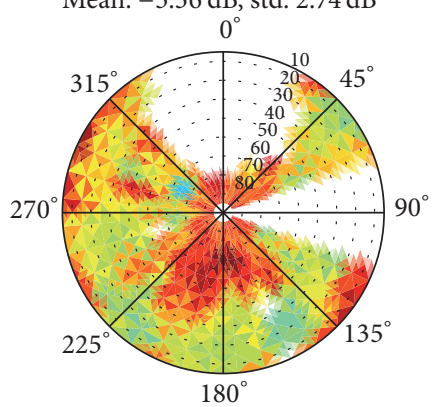

08-Aug-14-Aug

Mean: $-5.09 \mathrm{~dB}$, std: $2.63 \mathrm{~dB}$

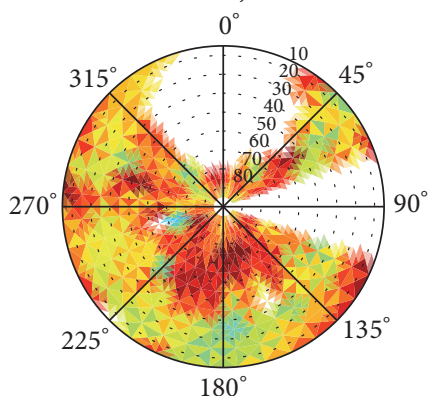

04-Jul-10-Jul

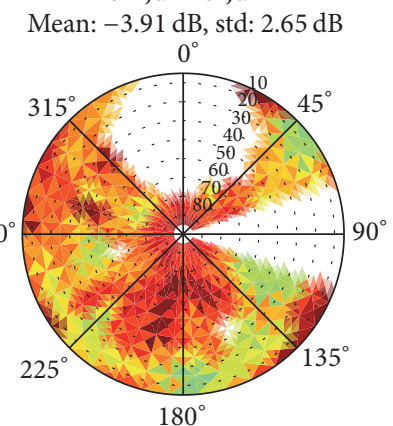

25-Jul-31-Jul

Mean: $-5.70 \mathrm{~dB}$, std: $2.72 \mathrm{~dB}$

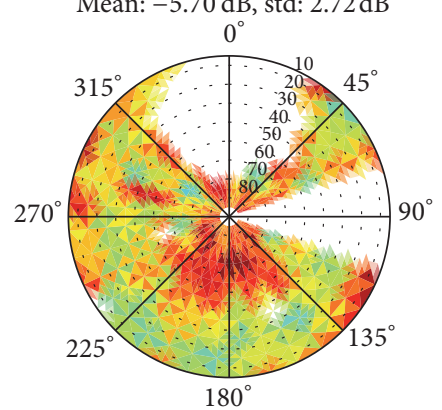

15-Aug-21-Aug

Mean: $-4.48 \mathrm{~dB}$, std: $2.81 \mathrm{~dB}$

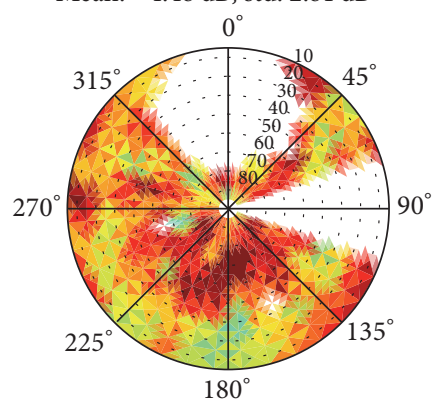

FIGURE 4: Temporal dynamics of weekly averaged values of GNSS signal attenuation $(L \mathrm{in} \mathrm{dB})$ as a function of azimuth and elevation angle $(10 \times 10$-degree bins). 


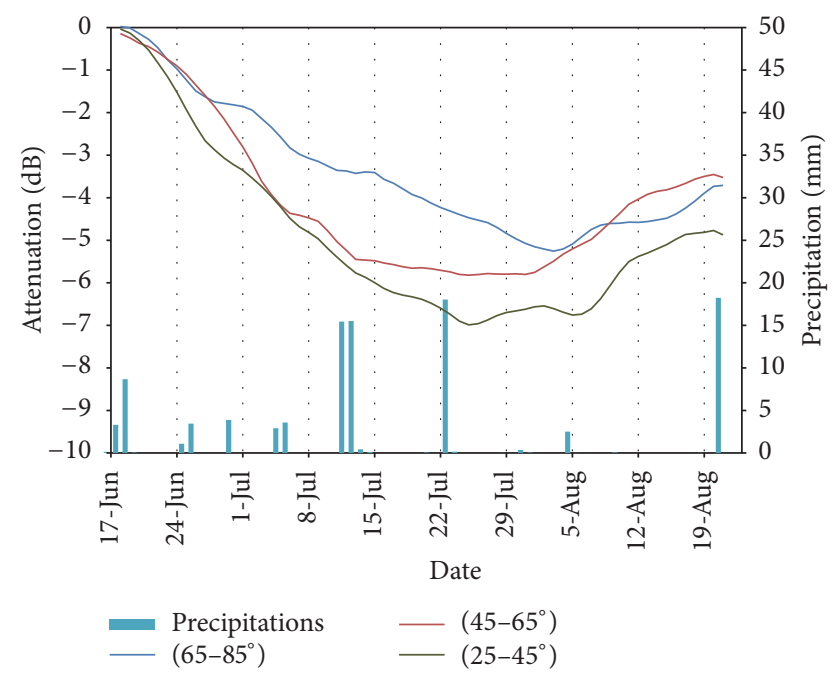

FIGURE 5: GNSS signal attenuation $(L)$ as a function of time, for three elevation ranges $\left(25-45^{\circ}, 45-65^{\circ}\right.$, and $\left.65-85^{\circ}\right)$.

noise effects which become significant at grazing angles of incidence.

At all elevations, the transmitted power clearly decreases during the first 6 weeks and then increases during the remaining weeks of the campaign. In addition to these general trends, various fluctuations can be seen during approximately the same weeks, at all observation angles. These fluctuations show a correlation with the strongest rainfall events plotted in Figure 5 and are thought to be produced by changes in the geometric structure of the sunflowers, produced either by precipitation and wind or by noise resulting from variations in the direct GNSS signal.

During the first measurement period, the GNSS signals reaching the ground can be seen to decrease over time, at all elevations. This trend is caused by the growth of vegetation cover, illustrated in Figure 2, which leads to an increase in signal attenuation. Although they are similar, the variations in attenuation shown in Figure 5 differ for each elevation range. At high elevations $\left(65^{\circ}-85^{\circ}\right)$, the transmitted GNSS signal is found to decrease until the beginning of August, with a maximum attenuation of approximately $5 \mathrm{~dB}$ when compared to that observed at the beginning of the campaign. After reaching this minimum in early August, the trend is reversed, with progressively stronger values of signal transmission. This decrease in attenuation occurs during the sunflower drying period, when the vegetation water content is decreasing, leading to progressively weaker attenuation of the $\mathrm{L}$ band signals.

At lower elevation angles $\left(25-45^{\circ}, 45-65^{\circ}\right)$, the GNSS signal attenuation is stronger, reaching a maximum of approximately $6 \mathrm{~dB}$ when compared to that observed at the beginning of the campaign. The attenuation maximum is reached during the third week of July, several days before the maximum value of VWC is reached. This could be caused by a signal saturation linked to the additional distance travelled in the vegetation by the signal at lower elevation.

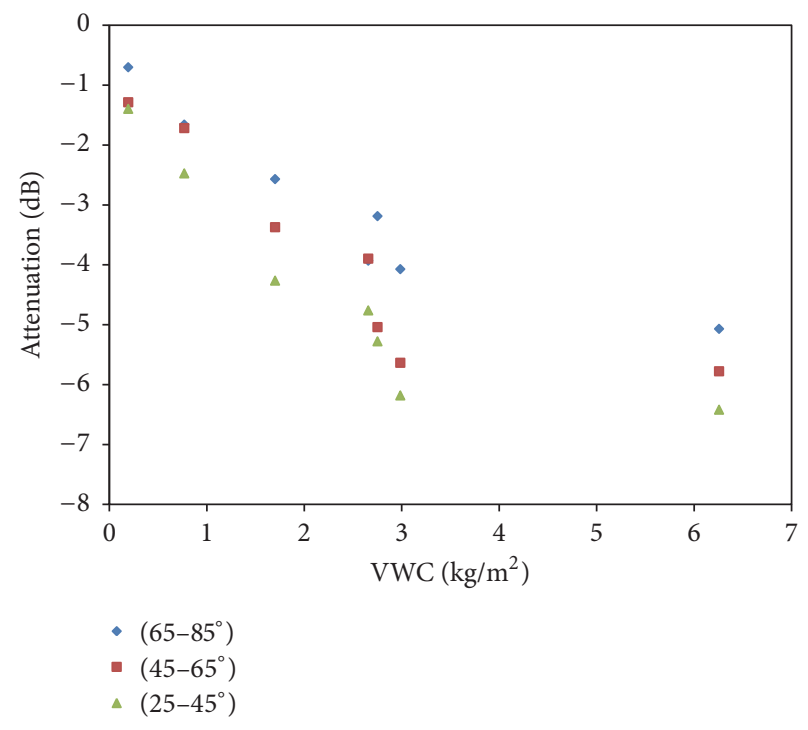

FIGURE 6: Dynamics of the GNSS signal attenuation $L$ as a function of VWC, for three elevation intervals $\left(65-85^{\circ} ; 45-65^{\circ}\right.$; and $\left.25-45^{\circ}\right)$.

These results provide a clear illustration of the considerable potential of GNSS signal analysis for the retrieval of vegetation cover properties and VWC in particular. A quantitative analysis of the relationship between GNSS signal attenuation and VWC is provided in the next section.

4.3. Relationship between GNSS Signals and Vegetation Properties. Figure 6 plots the computed daily values of GNSS signal attenuation for three different ranges of elevation $\left(65-85^{\circ}\right.$; $45-65^{\circ}$; and $25-45^{\circ}$ ), as a function of the in situ values of VWC. The highest elevation range $\left(65-85^{\circ}\right)$ provides the best potential for the retrieval of VWC, since in this case there is no saturation, and the signal decreases until the maximum value of VWC is reached $\left(6.2 \mathrm{~kg} / \mathrm{m}^{2}\right.$ in the present case). However, only a small decrease in signal is observed at VWC values greater than $3 \mathrm{~kg} / \mathrm{m}^{2}$. Figure 6 shows that, in the case of low elevations $\left(25-45^{\circ}\right)$, the signal attenuation saturates when the VWC reaches approximately $3 \mathrm{Kg} / \mathrm{m}^{2}$.

From these results, in order to examine the relationship between VWC and optical thickness, it is proposed to consider all VWC data.

Figure 7 plots the resulting relationship between optical thickness, defined in (3), and the ground truth measurements of VWC. For the three sets of elevation angle, we observe a linear relationship, allowing the constant $b$ defined in (4) to be determined. For the three ranges of elevation $\left(65-85^{\circ} ; 45-65^{\circ}\right.$; and $\left.25-45^{\circ}\right)$, very similar values are found for the parameter $b$ (Table 2). The maximum value of the VWC ground measurement appears to be very high, when compared to the measurement taken from the previous sample collection (12 days before). An increase in VWC of more than $3 \mathrm{~kg} / \mathrm{m}^{2}$ seems very high for such a short period of time and with a constant height. This increased biomass could be due to the influence of inappropriate sample selection as some heterogeneity exists around the point of GNSS 


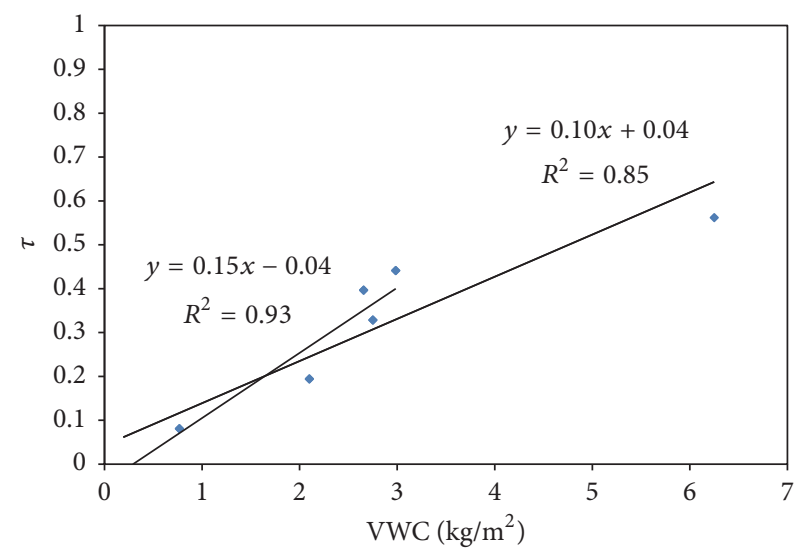

(a)

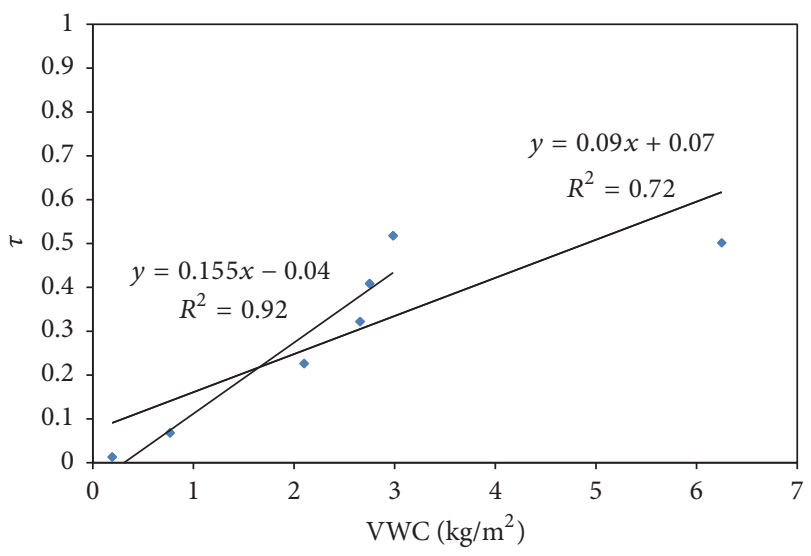

(b)

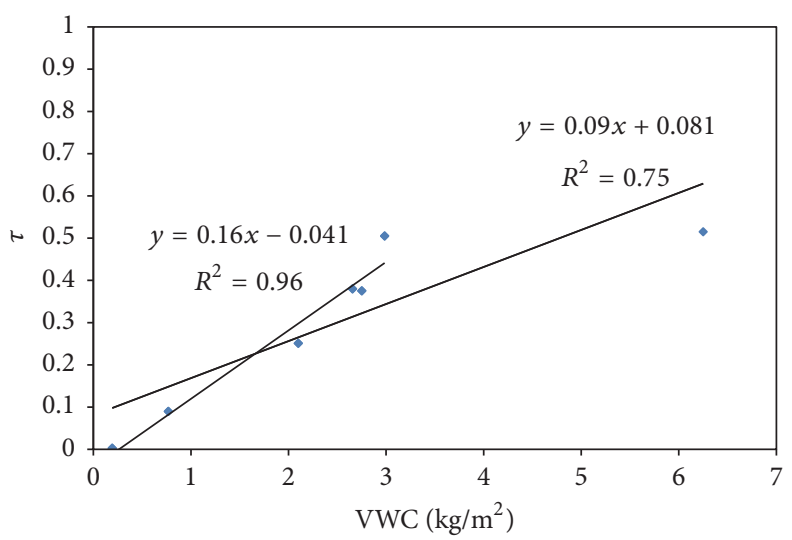

(c)

FIGURE 7: Relationship between ground truth VWC measurements and the retrieved values of optical thickness $(\tau)$, for three ranges of GNSS signal elevation angle (a) $65-85^{\circ}$; (b) $45-65^{\circ}$; and (c) $25-45^{\circ}$.

TABLE 2: $b$ values and correlation coefficients $\left(R^{2}\right)$ between VWC and optical thickness, for the elevation angle ranges $65-85^{\circ} ; 45-65^{\circ}$; and $25-45^{\circ}$.

\begin{tabular}{lcccc}
\hline & & $65-85^{\circ}$ & $45-65^{\circ}$ & $25-45^{\circ}$ \\
\hline \multirow{2}{*}{ With all VWC data } & $b$ & 0.1 & 0.09 & 0.09 \\
& $R^{2}$ & 0.85 & 0.72 & 0.75 \\
Without outlier & $b$ & 0.15 & 0.155 & 0.16 \\
& $R^{2}$ & 0.93 & 0.92 & 0.96 \\
\hline
\end{tabular}

measurements. If this measurement point is considered as an outlier and removed from the dataset, the correlation between the VWC and the optical thickness greatly improves and values of $b$ around 0.15 are retrieved, as shown in Figure 7 and Table 2. These values of $b$ ranging between 0.1 and 0.16 are typical of those retrieved in microwave applications for the estimation of VWC [15].

This aspect needs to be analyzed more in-depth in the future with other more intensive experimental campaigns.

4.4. VWC Estimation. Figure 8 plots the daily variation in $\mathrm{VWC}$, for three ranges of elevation angle $\left(65-85^{\circ}, 45-65^{\circ}\right.$, and $25-45^{\circ}$ ) computed from the retrieved relationships between optical thickness and VWC, using a value of approximately 0.15 for the parameter $b$. These results are compared with the ground measurements (recorded on six different dates), thus revealing a very good agreement between the GNSSbased estimations and ground measurements, over a wide range of elevation angles. Although these results indicate small discrepancies between the retrieved values of VWC, at different ranges of elevation angle, the GNSS signal attenuation technique can clearly provide accurate estimations of the water content of annual vegetation cover such as that of sunflower fields.

\section{Conclusions}

In the present study, we discuss the potential of GNSS signals for the monitoring of vegetation dynamics. An instrument based on a pair of two low-cost GPS receivers and their antennas, one placed on the ground below the vegetation cover and the other at the top of a 2 m mast (reference), was used to measure GNSS signals attenuation in a sunflower test field, over a period of more than two months. The GNSS signals attenuation is found to have an azimuthal sensitivity 


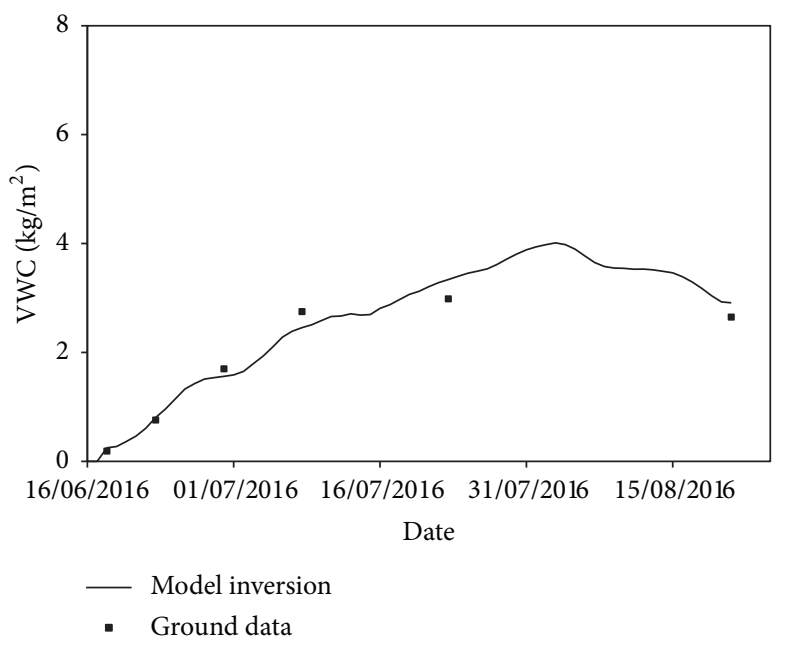

(a)

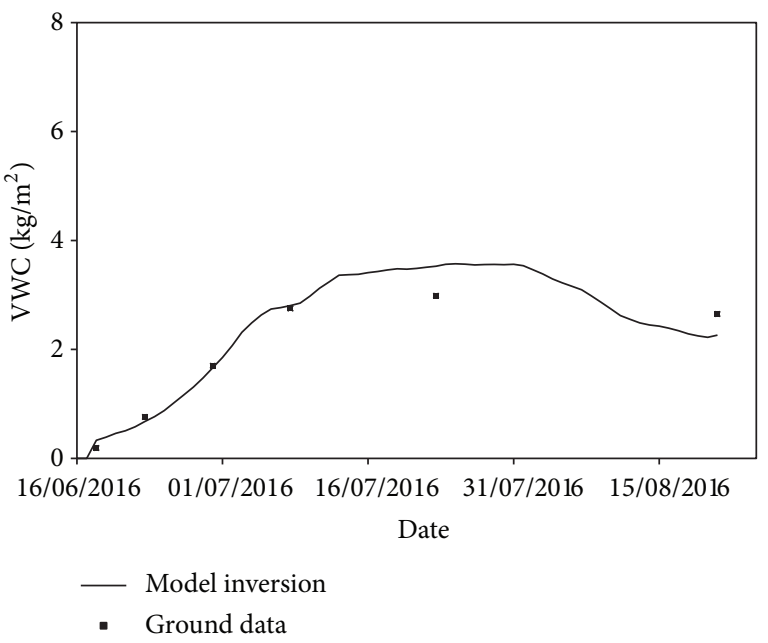

(b)

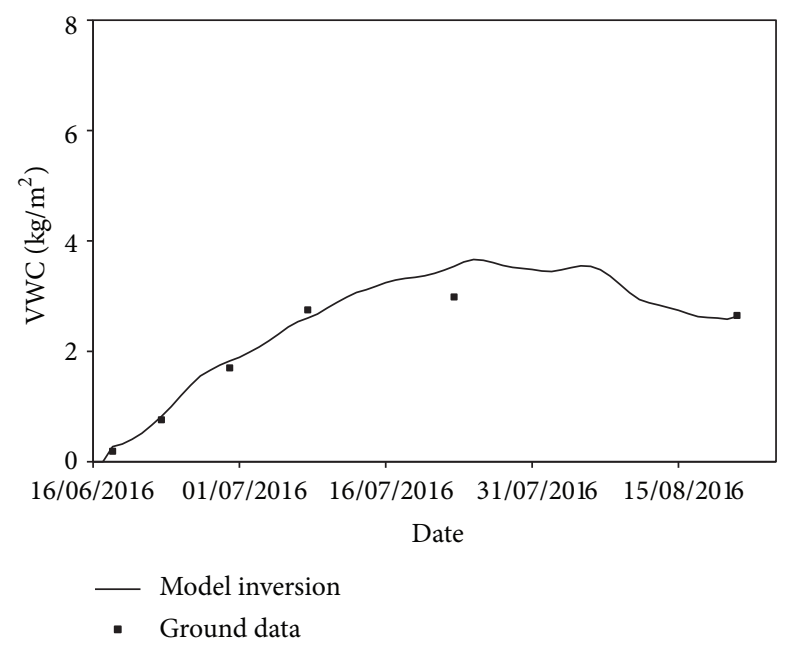

(c)

FIGURE 8: Daily VWC estimations using GNSS signals, compared to ground measurements for three ranges of GNSS signal elevation angle: (a) $65-85^{\circ}$; (b) $45-65^{\circ}$; and (c) $25-45^{\circ}$.

at high elevation angles in particular and at the beginning of the vegetation cycle, mainly as a consequence of the directional structure of the vegetation. A strong correlation is observed between VWC and GNSS signal attenuation. The GNSS signals are strongly attenuated $(>6 \mathrm{~dB})$ when the vegetation reaches a certain level of growth. This occurred during the third week of July at low elevation angles; that is, two weeks before the sunflower plants had attained maximum growth, with a VWC of approximately $3 \mathrm{~kg} / \mathrm{m}^{2}$. Maximum attenuation was reached several days later in the case of GNSS measurements made at high elevation angles, corresponding to a maximum recorded VWC equal to $6.2 \mathrm{~kg} / \mathrm{m}^{2}$. The observed temporal dynamics of the GNSS signal attenuation reveal fluctuations in the incident GNSS signals, which can be affected by precipitation events in particular.

The estimated optical thickness can be modeled as a linear function of the VWC. The factor $b$ (see (4)) is thus determined as approximately 0.09 , for all elevation angles between $25^{\circ}$ and $85^{\circ}$, with a correlation coefficient of $\sim 0.75$. There is a doubt about the validity of the highest VWC measurement point, as its value seems too high, especially in comparison to the previous and following measurements. If this point is removed from the dataset, retrieved $b$ values are found to be around 0.15 which would confirm what is already found in the literature, and the correlation coefficient $R^{2}$ increases to $\sim 0.95$. The VWC was estimated on a daily basis over the study period, using the proposed algorithm to invert the GNSS signal attenuation measurements. Although this study was affected by various imperfections, in particular the accuracy and frequency of ground measurements, noise affecting the GNSS signals (due mainly to fluctuations in atmospheric transmission) and simplifying assumptions in the optical thickness retrieval model (which does not account for various physical effects, such as cover refraction and reflection, produced by the vegetation medium), it has demonstrated the considerable potential of GNSS signal measurements for the nondestructive in situ retrieval of vegetation water content (VWC), especially for agricultural applications. This type of 
measurement could also be used to improve the analysis of $\mathrm{L}$ band microwave satellite signals interactions with vegetation covered soils. In future studies, further measurements will be carried out in order to evaluate other potential applications allowing the nondestructive in situ estimation of agricultural covers, without requiring the presence of operators. Different questions linked to elevation and azimuth effect of GNSS signals and vegetation geometry require more measurements and theoretical analysis.

\section{Conflicts of Interest}

The authors declare that there are no conflicts of interest regarding the publication of this paper.

\section{Acknowledgments}

This study was funded by the TOSCA/CNES GLORIE and PRISM/RTRA projects. Observation data were collected at the Regional Spatial Observatory (OSR). OSR facilities and staff are funded and supported by the Observatory MidiPyrenean, the Paul Sabatier University, Toulouse, France, CNRS, CNES, and IRD. ICOS-France is also gratefully acknowledged for funding observation data of Auradé site. The authors wish to thank the teams from CESBIO for their support.

\section{References}

[1] S. Saux-Picart, C. Ottlé, B. Decharme et al., "Water and energy budgets simulation over the AMMA-Niger super-site spatially constrained with remote sensing data," Journal of Hydrology, vol. 375, no. 1-2, pp. 287-295, 2009.

[2] A. G. Konings, A. P. Williams, and P. Gentine, "Sensitivity of grassland productivity to aridity controlled by stomatal and xylem regulation," Nature Geoscience, vol. 10, no. 4, pp. 284-288, 2017.

[3] N. Baghdadi and M. Zribi, Optical Remote Sensing of Land Surfaces, Techniques and Methods, ISTE Press, London, UK; Elsevier, Oxford, UK, 2016.

[4] N. Baghdadi and N. M. Zribi, Microwave Remote Sensing of Land Surfaces, Techniques and Methods, ISTE Press, London, UK; Elsevier, Oxford, UK, 2016.

[5] M. Zribi, M. Pardé, J. Boutin et al., "CAROLS: A new airborne L-band radiometer for ocean surface and land observations," Sensors, vol. 11, no. 1, pp. 719-742, 2011.

[6] G. Fontanelli, S. Paloscia, M. Zribi, and A. Chahbi, "Sensitivity analysis of X-band SAR to wheat and barley leaf area index in the Merguellil Basin," Remote Sensing Letters, vol. 4, no. 11, pp. 1107-1116, 2013.

[7] M. Martin-Neira, "A passive reflectometry and interferometry system (PARIS): application to ocean altimetry," ESA Journal, vol. 17, no. 4, pp. 331-355, 1993.

[8] V. U. Zavorotny, S. Gleason, E. Cardellach, and A. Camps, "Tutorial on remote sensing using GNSS bistatic radar of opportunity," IEEE Geoscience and Remote Sensing Magazine, vol. 2, no. 4, pp. 8-45, 2014.

[9] E. Motte, A. Egido, N. Roussel, K. Boniface, and F. Frappart, "Applications of GNSS-R in continental hydrology," in Land Surface Remote Sensing in Continental Hydrology, N. Baghdadi and M. Zribi, Eds., pp. 281-322, ISTE Press, London, UK; Elsevier, Oxford, UK, 2016.

[10] N. Rodriguez-Alvarez, A. Camps, M. Vall-Llossera et al., "Land geophysical parameters retrieval using the interference pattern GNSS-R technique," IEEE Transactions on Geoscience and Remote Sensing, vol. 49, no. 1, pp. 71-84, 2011.

[11] E. E. Small, K. M. Larson, and J. J. Braun, "Sensing vegetation growth with reflected GPS signals," Geophysical Research Letters, vol. 37, no. 12, 2010.

[12] A. Egido, S. Paloscia, E. Motte et al., "Airborne GNSS-R polarimetric measurements for soil moisture and above-ground biomass estimation," IEEE Journal of Selected Topics in Applied Earth Observations and Remote Sensing, vol. 7, no. 5, pp. 15221532, 2014

[13] E. Motte, M. Zribi, P. Fanise et al., "GLORI: A GNSS-R dual polarization airborne instrument for land surface monitoring," Sensors, vol. 16, no. 5, article no. 732, 2016.

[14] F. Koch, M. Prasch, L. Schmid, J. Schweizer, and W. Mauser, "Measuring snow liquid water content with low-cost gps receivers," Sensors, vol. 14, no. 11, pp. 20975-20999, 2014.

[15] F. Koch, F. Schlenz, M. Prasch, F. Appel, T. Ruf, and W. Mauser, "Soil moisture retrieval based on GPS signal strength attenuation," Water, vol. 8, no. 7, article 276, 2016.

[16] W. C. Wright, P. W. Liu, K. C. Slatton, R. L. Shrestha, W. E. Carter, and H. Lee, "Predicting L-band microwave attenuation through forest canopy using directional structuring elements and airborne lidar," in Proceedings of the 2008 IEEE International Geoscience and Remote Sensing Symposium, pp. III688-III691, Boston, Mass, USA, July 2008.

[17] N. Rodriguez-Alvarez, X. Bosch-Lluis, A. Camps et al., "Vegetation water content estimation using gnss measurements," IEEE Geoscience and Remote Sensing Letters, vol. 9, no. 2, pp. 281-286, 2012.

[18] SiRFstarIV ${ }^{\mathrm{TM}}$, One Socket Protocol Interface Control Document, 2012.

[19] F. T. Ulaby, R. K. Moore, and A. K. Fung, Microwave Remote Sensing: Active and Passive, Artech House, Norwood, MA, USA, 1981.

[20] T. J. Jackson, T. J. Schmugge, and J. R. Wang, "Passive microwave sensing of soil moisture under vegetation canopies," Water Resources Research, vol. 18, no. 4, pp. 1137-1142, 1982. 


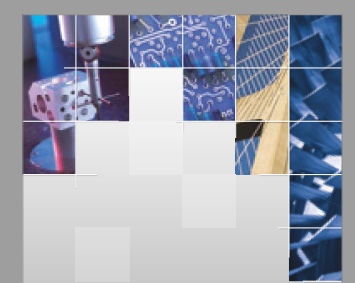

\section{Enfincering}
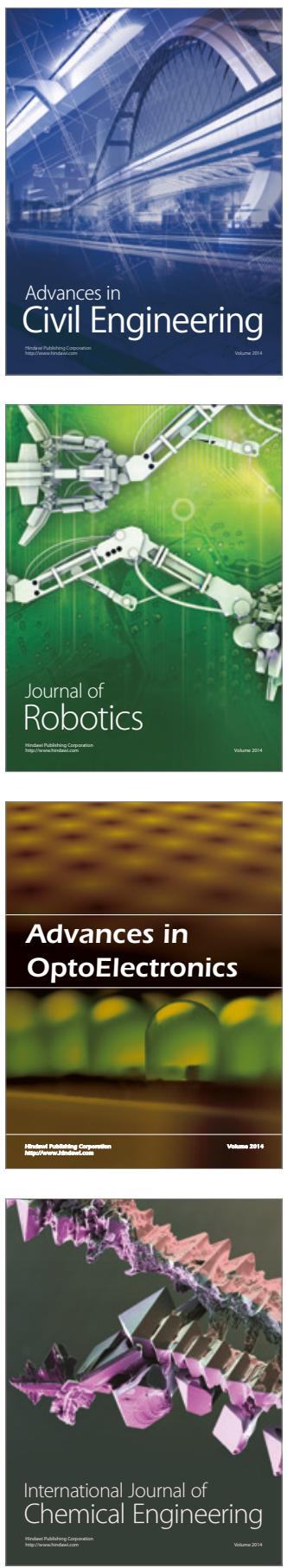

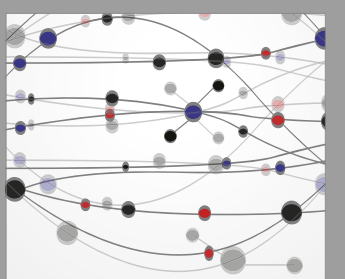

The Scientific World Journal

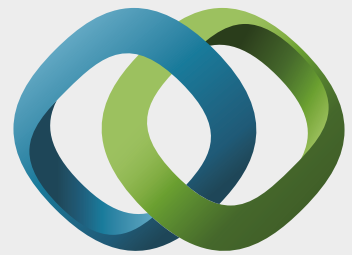

\section{Hindawi}

Submit your manuscripts at

https://www.hindawi.com
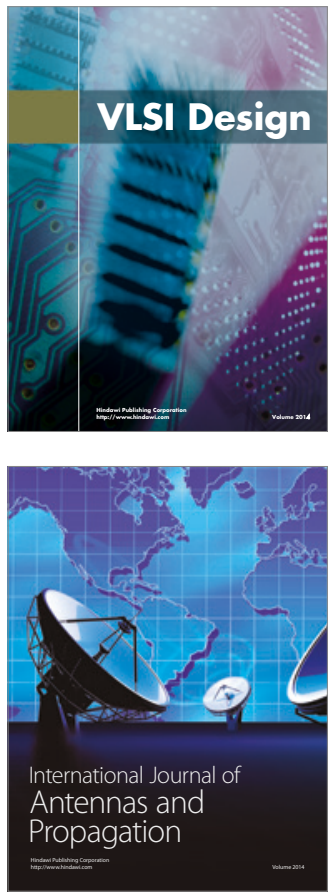

\section{Rotating}

Machinery
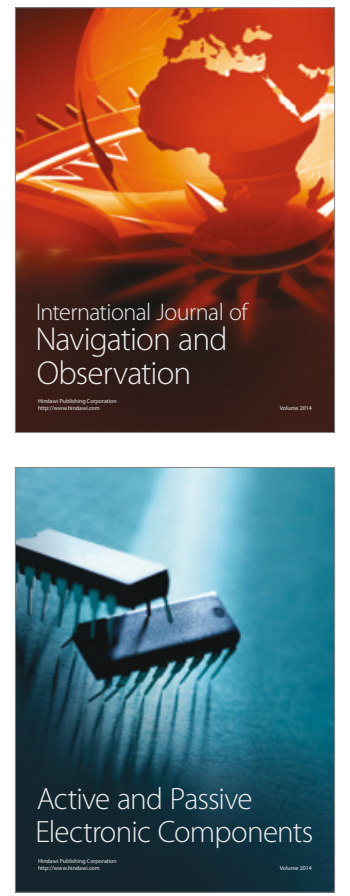
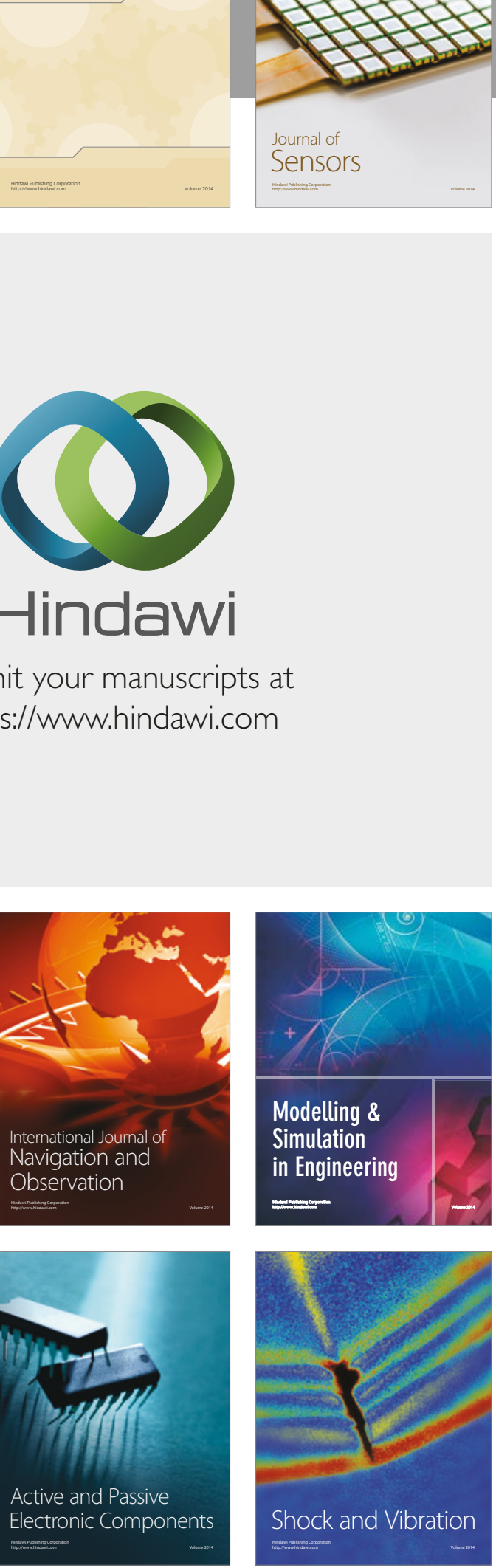
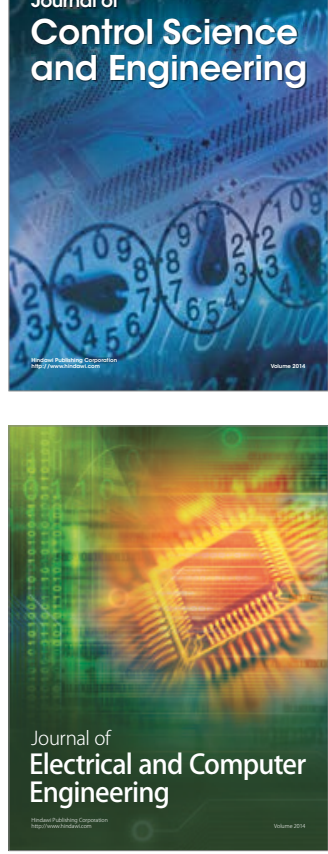

Distributed

Journal of

Control Science

and Engineering
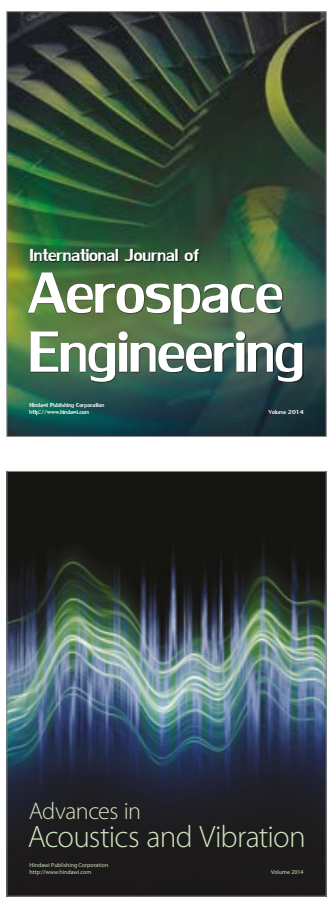

Sensor Networks 